\title{
Effect of Gut Microbes from Eyprepocnemis alacris alacris (Serv. 1838) against Culex quinquefasciatus Say- An Ecofriendly Approach
}

\author{
Soorya Sukumaran, Rajan Maheswaran* \\ Entomology Laboratory, Department of Zoology, School of Life Sciences, Periyar University, India
}

Received February 13, 2020; Revised March 23, 2020; Accepted March 28, 2020

Copyright $\bigcirc 2020$ by authors, all rights reserved. Authors agree that this article remains permanently open access under the terms of the Creative Commons Attribution License 4.0 International License

\begin{abstract}
Mosquitoes are on focus worldwide because of its role as vectors for devastating parasites and pathogens causing a threat to millions of people worldwide. Vector-borne diseases in mosquitoes are transmitted by females. However, ineffectiveness of insecticides increases the resistance in mosquitoes. The administration of new vector control strategies against the mosquitoes needs the implementation of microbial insecticides. In this study was commenced to determine the mortality of larvae using gut bacteria as of Eyprepocnemis alacris alacris (Serville, 1838) conflict to larvae laboratory conditions to identify an effective bacteria. The results indicated the existence of larvicidal activity in 106 isolates and were found to appear strongly effective activity in three isolates against $C x$. quinquefasciatus. Cent per cent mortality was observed from each of the secondary metabolites. The recorded values of $\mathrm{LC}_{50}$ were 6.66, 7.13 and 7.64ppm and $\mathrm{LC}_{90}$ has been $115.90,205.73$ and 242.59 ppm respectively. The sequencing and phylogenetic analysis confirmed that these 3 isolates were identified as Klebsiella pneumoniae, Enterobacter xiangfangensis and Ochrobactrum intermedium respectively. Our results showed high larvicidal potential effect against to these bacteria. Outcome of these work highlight the alternative use of synthetic chemical pesticides to control mosquitoes.
\end{abstract}

Keywords Culex quinquefasciatus, Larvicidal Activity, Klebsiella pneumoniae, Enterobacter xiangfangensis, Ochrobactrum Intermedium

\section{Introduction}

Mosquitoes are one of the major nuisances found more than 30 million years spreading epidemic and disease to humans and their helpful resources like animals globally
[1]. Mosquitoes belong to arthropods and they transmit parasites and pathogens through their piercing and sucking type of mouthparts to human beings [2]. Mosquitoes are expected to convey the ailment more than 700 million people per annum; bites are regularly an annoying nuisance, but still cause some diseases like malaria, dengue fever, yellow fever, etc., every year [(James 1992)].

$C x$. quinquefasciatus Say is a cosmopolitan mosquito vector of lymphatic filariasis and Japanese encephalitis. It causes millions of deaths every year, especially in India and Africa [3, 4]. Human filariasis caused by Wuchereria bancrofti is a major public health hazard and remains a challenging socioeconomic problem in many of the tropical countries [5]. It is widely distributed in tropical zones with around 120 million people infected worldwide and 44 million people having common chronic manifestation [6] and has a very low control priority [7]. These filarial nematodes are usually characterized by progressive debilitating swelling at the extremities, scrotum, or breast (elephantiasis) in an infected individual [8].

Vector control is a very important part of the global strategy for the management of mosquito-borne diseases and insecticide application is the most important component in this effort. The main tool being used to combat mosquitoes are conventional pesticides but the application of synthetic pesticides can cause health problems and adversely affect the environment $[9,10]$. The resurgence of mosquito-borne diseases is due to the development of insecticide resistance and the drug resistance of pathogens [11]. A large number of studies have shown that multiple, complex resistance mechanisms such as, increased metabolic detoxification of insecticides and decreased the sensitivity of the target proteins or genes are likely responsible for insecticide resistance. However, no comprehensive understanding of the resistance mechanisms or regulation involved has been yet been 
developed [12].

Consequently, synthetic chemical pesticides should be altered by effective and safe natural insecticides such as plant-derived essential oils, extracts and their compounds [13-17]. Insect-bacterial symbioses are widespread in the environment [18] and antibiotic-producing bacterial symbionts are often used to protect the host and/or their resources [19]. So far the most successful bio insecticide used, in order to combat mosquito larvae are Bacillus thuringiensis $[20,21]$.

Most of the agricultural insects act as pests and are responsible for immense losses in crop plants [22]. Locusts and grasshoppers (Orthoptera: Acridoidea) are among the most perilous pests to tree seedlings and agricultural crops [23]. Synthetic insecticides have relied on traditionally for control of grasshoppers and locusts [24]. However, the high costs of emergency control and eco-friendly management and growing awareness are expanding the demand for biological control [25]. However, symbiotic bacteria residing in the gut of Eyprepocnemis alacris alacris also introduce a promising solution as a biocontrol agent for pest control management.

Microbial colonization in an insect gut is due to distinctive environments and provides many beneficial services to their hosts [26]. Symbiotic bacteria exist in the entomopathogenic nematodes also bring as a biocontrol agent for pest control management [27]. In the natural and human-impacted ecosystems insects and their gut microbial communities regarded as the intermediary of biogeochemical cycles [28, 29].

The current study was conducted for laboratory assessment of the mosquito larvicidal activity of E. alacris alacris (short-horned grasshopper) gut microbes against early fourth instar larvae of Culex quinquefasciatus.

\section{Materials and Methods}

\subsection{Compilation of Insects}

Short-horned grasshoppers, Eyprepocnemis alacris alacris (Serville, 1838) (Orthoptera: Acrididae) have been compilated from campus area of Periyar University in Salem (Latit. 11.650 N: Long. 78.16E), Tamil Nadu, India. The environmental conditions of the study area for example the temperature; humidity and precipitation were $27^{\circ} \mathrm{C}, \quad 86 \%$ and $60 \%$ respectively. The adult insects were collected using the sweep net on grasses; bushes and other crop fields such as paddy, sugar cane and maize field etc., and fetched to the laboratory in polypropylene containers [30].

\subsection{Isolation and Characterization of Cultivated Bacteria from Insect Digestive Tract}

The collected insects were surface sterilized with iodine and $70 \%$ ethanol, further to remove the traces of ethanol insect was cleaned with sterile water. According to the modified procedure of [31], twenty $(20 \mathrm{~N})$ of adult insects cooled and dissections were performed on ice [32]. The dissected gut tissue was washed in IX phosphate-buffered saline (PBS; $150 \mathrm{mM} \mathrm{NaCl}$ in $20 \mathrm{mM} \mathrm{Na}+/ \mathrm{K}+$ phosphate buffer, $\mathrm{pH}$ 7.4) and was pooled into microcentrifuge tubes with $100 \mu 1$ of PBS [33]. Furthermore, $1 \mathrm{ml}$ of gut extracts was homogenized in $10 \mathrm{mM}$ PBS in a Ten Broeck Homogenizer [34]. The homogenates have been vortexes for $10 \mathrm{sec}$ to detach the cells of bacteria from the suspension of gut. Gut extracts have been stored frozen at $-20^{\circ} \mathrm{C}$. The serially diluted gut suspension was plated on the respective media and pro to incubate for $24 \mathrm{hrs}$ at $37^{\circ} \mathrm{C}$ [35]. Each colony was purified through continuous streaking on agar plates.

\section{Test for Mosquito's Larvicidal Activity}

\subsection{Mosquito's Culture}

Larvae of C. quinquefasciatus were collected as of the leftovers of sluggish water in various places of Periyar University, Salem. Colonization and maintenance of the larvae for generations have been continued by using the procedure $[36,37]$ to avoid external contaminants. To avoid the toxicity due to scum formation in water it was changed every day.

\subsection{Larvicidal Analysis}

Modified method was used to evaluate the devastation of larvae [38]. Early IV instar of $25 C x$. quinquefasciatus larvae have been emancipated in $1.0 \mathrm{ml}$ of microbial cultures containing $249 \mathrm{ml}$ of distilled water at different concentrations. A proper distilled water control has been maintained along with the ten replicates of all concentrations. The exposure phase subsequent to $24 \mathrm{hrs}$ fatality and endurance rate have been documented. Percentage of fatality of larvae in each treated concentration was calculated by motile larva were combined with control group larvae in all replicates. Confirmation of the fatal larvae in the experiment was done by perplexing the cervical region [39]. Moribund larvae were those incapables of rising to the surface (within a reasonable period of time) or showing the characteristic diving reaction when the water was disturbed.

\subsection{Statistical Analysis}

The $\mathrm{LC}_{50}$ and $\mathrm{LC}_{90}$ values of larval fatality in each concentration of trials have been calculated by applying EPA Probit analysis programme [40]. 


\section{Identification of Selected Bacteria}

\subsection{Colony Morphology and Biochemical Tests}

The effective three bacterial strains from the insect gut were isolated from nutrient agar was further subcultured on fresh sterile agar plates by a streak plate method and incubated $37^{\circ} \mathrm{C}$ for $24 \mathrm{hrs}$. According to the Bergey's manual, the selected three bacterial strains have been analyzed and its colony characteristic, biochemical properties were documented through visual and light microscopic observations [41, 42].

\section{Molecular Identification}

\subsection{Genomic DNA Extraction of Bacteria}

Genomic DNA extraction of bacteria was carried out by means of InstaGene ${ }^{\mathrm{TM}}$ Matrix Genomic DNA Isolation kit. As per the directions the kit DNA was extracted [43].

\subsection{Amplification of PCR and Purification of Products}

27F AGAGTTTGATCMTGGCTCAG 20 and 1492R TACGGYTACCTTGTTACGACTT 22 and universal primers gene fragment was used for PCR amplification. Purification of PCR was done by Montage PCR Clean up kit (Millipore). Sequencing reactions have been done with AmpliTaq ${ }^{\circledR}$ DNA polymerase (FS enzyme) (Applied Biosystems).

\subsection{Sequencing and Phylogenetic Analysis}

NCBI blast tool was applied for identification of sequence similarity [44]. Phylogenetic analysis was done with PhyML 3.0 aLRT program with HKY85 as a model substitution. Tree 198.3 program have been applied for tree rendering [45].

\section{Results}

\subsection{Screening of Selected Bacterial Strains from the Gut of Insect}

In our experiment 106 strains of bacteria have been screened in insect gut of E.alacris alacris. The results are presented in Figure 1.

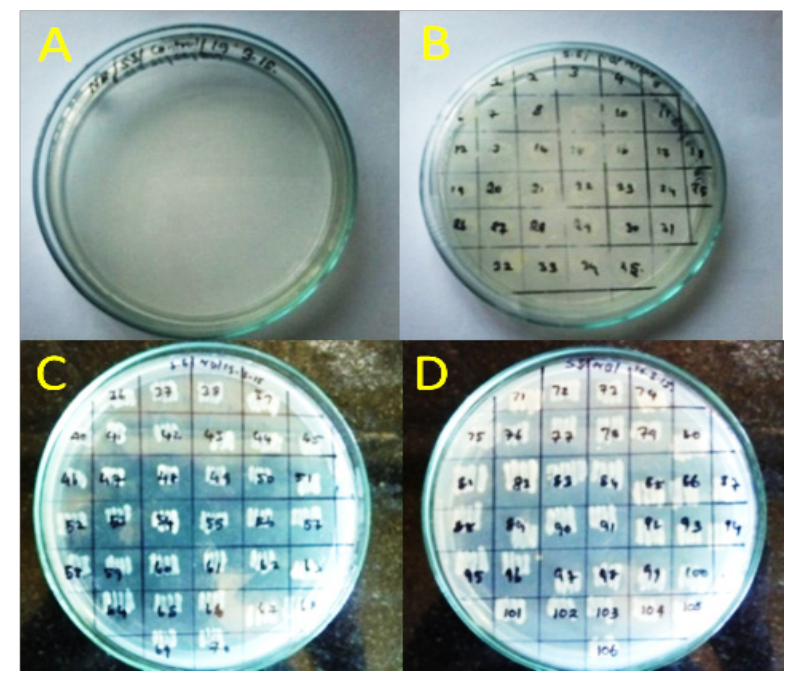

A) Control; B, C, D) Isolated bacteria on nutrient agar plates

Figure 1. Isolation of bacterial strains from the gut of insect

\subsection{Larvicidal Bioassay}

All the bacterial metabolites (from 106 strains) exhibited larvicidal activity against $C x$. quinquefasciatus subsequent to $24 \mathrm{hrs}$ of the exposure phase. Among the secondary metabolites tested, an experiential larvicidal activity found in three bacterial strains. Based upon their $\mathrm{LC}_{50}$ and $\mathrm{LC}_{90}$ values the selected strains were S7, S8 and S37. Values of $\mathrm{LC}_{50}$ of $\mathrm{S} 7, \mathrm{~S} 8$ and $\mathrm{S} 37$ were $6.66 \mathrm{ppm}, 7.13 \mathrm{ppm}$ and $7.64 \mathrm{ppm}$ respectively. $\mathrm{LC}_{90}$ values of $\mathrm{S} 7, \mathrm{~S} 8$ and $\mathrm{S} 37$ were $115.90 \mathrm{ppm}, 205.73 \mathrm{ppm}$ and $242.59 \mathrm{ppm}$ respectively (Table 1).

Table 1. Larvicidal activity of Eyprepocnemis alacris alacris guts microbes against the larvae of C. quinquefasciatus (Say) at $24 \mathrm{hrs}$

\begin{tabular}{|c|c|c|c|c|c|c|c|}
\hline \multirow{2}{*}{ Mosquito species } & \multirow{2}{*}{ Microbial Culture } & \multirow{2}{*}{$\mathrm{LC}_{50}$} & \multicolumn{2}{|c|}{ 95\% Confidence Limits } & \multirow{2}{*}{$\mathrm{LC}_{90}$} & \multicolumn{2}{|c|}{$\begin{array}{c}95 \% \\
\text { Confidence Limits }\end{array}$} \\
\hline & & & LCL & $\mathrm{UCL}$ & & LCL & UCL \\
\hline \multirow{3}{*}{ Culex quinquefasciatus } & Klebsiella pneumoniae (S7) & 6.66 & 0.43 & 19.46 & 115.90 & 70.27 & 170.07 \\
\hline & Enterobacter xiangfangensis (S8) & 7.13 & 0.49 & 20.46 & 205.73 & 133.76 & 344.03 \\
\hline & Ochrobactrum intermedium (S37) & 7.64 & 0.68 & 19.99 & 242.59 & 160.03 & 427.82 \\
\hline
\end{tabular}



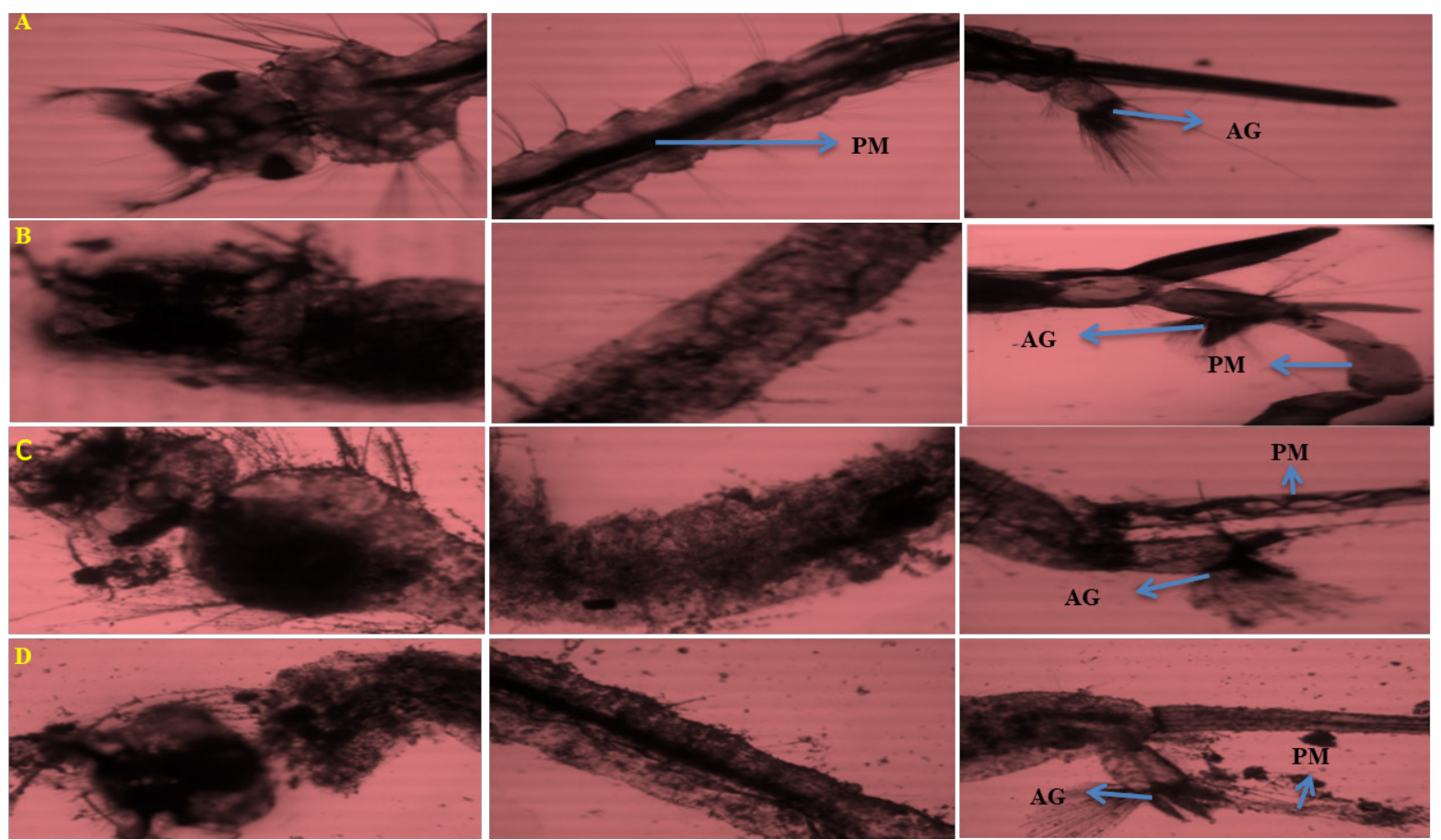

A: Control; B: S7; C: S8; D: S37; AG: Anal Gills; PM: Peritrophic Membrane

Figure 2. Peritrophic membrane and anal gills of dead larvae of $C x$. quinquefasciatus

In the present investigation different larval symptoms were observed throughout the experimental period. In the initial stages of experimental study larvae have been vigorous and have typical movement. After that, each larva possessed a slight variation in their movement. After $24 \mathrm{hrs}$ time interval the fatal larvae have been depicted under light microscope, where the body attained dark blackish colour, expatriation of peritrophic membrane and anal gills from the digestive system can be observed in the anal region and the internal part of the body and outer layer of skin were eroded (Figure 2).

\subsection{Colony Morphology and Biochemical Tests}

Bergey's manual of determinative bacteriology was used to analyse the genus level of each strains primarily. Gram staining of the three strains from insect gut using a light microscope showed that the three strains were Gram-negative and rod-shaped (Table 2). The analysed 3 strains were belonged to Klebsiella, Enterobacter and Ochrobactrum genera. The strain S7, S8 \& S37 showed a positive reaction on citrate utilization, urease, nitrate reduction, glucose, lactose and arabinose production and no reaction on $\mathrm{H}_{2} \mathrm{~S}$ production, lysine \& ornithine utilization. S7 \& S8 also showed a positive reaction on phenylalanine deamination, sorbitol and adonitol but S37 have no reaction phenylalanine deamination, sorbitol and adonitol production (Table 3).

\subsection{Molecular Identification of Selected Gut Bacteria}

Molecular identification of the three strains showed a high degree of similarities when contrasting the contig regions with NCBI GenBank entries using BLAST algorithm (http://www.ncbi.nlm.nih.gov) revealed to S7 strains have $93 \%$ maximum identity with a sequence of Klebsiella pneumoniae, S8 strains has $86 \%$ similarity with Enterobacter xiangfangensis and 78\% similarity with (S37) Ochrobactrum intermedium (Figure 3, 4, 5). Neighbour-joining method was used to construct the phylogenetic tree. 
Table 2. Colony morphology and physiology of isolated bacterial strains

\begin{tabular}{|c|c|c|c|}
\hline Characteristic features & $\begin{array}{c}\text { Klebsiella pneumoniae } \\
\text { (S7) }\end{array}$ & $\begin{array}{c}\text { Enterobacter xiangfangensis } \\
\text { (S8) }\end{array}$ & $\begin{array}{c}\text { Ochrobactrum intermedium } \\
\text { (S37) }\end{array}$ \\
\hline Gram stain & - & $\mathrm{R}$ & - \\
\hline Morphology & $\mathrm{R}$ & - & $\mathrm{R}$ \\
\hline Spores & - & - & - \\
\hline Motility & - & Cream & - \\
\hline
\end{tabular}

(R)- rode shaped, $(+)$ - Positive, $(-)$ - negative

Table 3. Biochemical analysis of selected bacteria

\begin{tabular}{|c|c|c|c|}
\hline Tests & $\begin{array}{c}\text { Klebsiella pneumonia } \\
\text { (S7) }\end{array}$ & $\begin{array}{c}\text { Enterobacter xiangfangensis } \\
(\mathrm{S} 8)\end{array}$ & $\begin{array}{c}\text { Ochrobactrum intermedium } \\
(\mathrm{S} 37)\end{array}$ \\
\hline Citrate Utilization & + & + & + \\
\hline Lysine Utilization & - & - & - \\
\hline Ornithine Utilization & - & - & - \\
\hline Urease & + & + & + \\
\hline Phenylalanine Deamination & + & + & - \\
\hline Nitrate Reduction & + & + & + \\
\hline $\mathrm{H}_{2} \mathrm{~S}$ Production & - & - & - \\
\hline Glucose & + & + & + \\
\hline Adonitol & + & + & - \\
\hline Lactose & + & + & + \\
\hline Arabinose & + & + & + \\
\hline Sorbitol & + & + & - \\
\hline
\end{tabular}

(+): Positive Reaction, (-): Negative Reaction 
Effect of Gut Microbes from Eyprepocnemis alacris alacris (Serv. 1838) against Culex quinquefasciatus Say- An Ecofriendly Approach

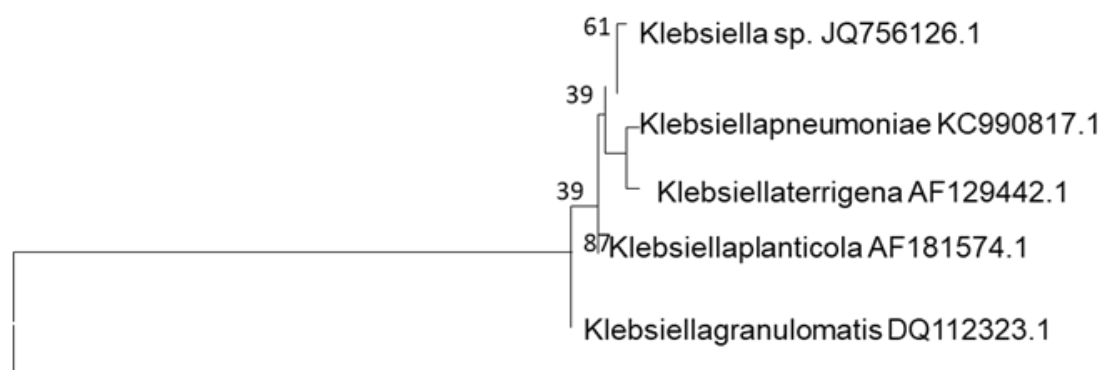

Klebsiellaoxytoca FJ424514.1

0.1

Figure 3. Phylogenetic tree of Klebsiella pneumoniae.

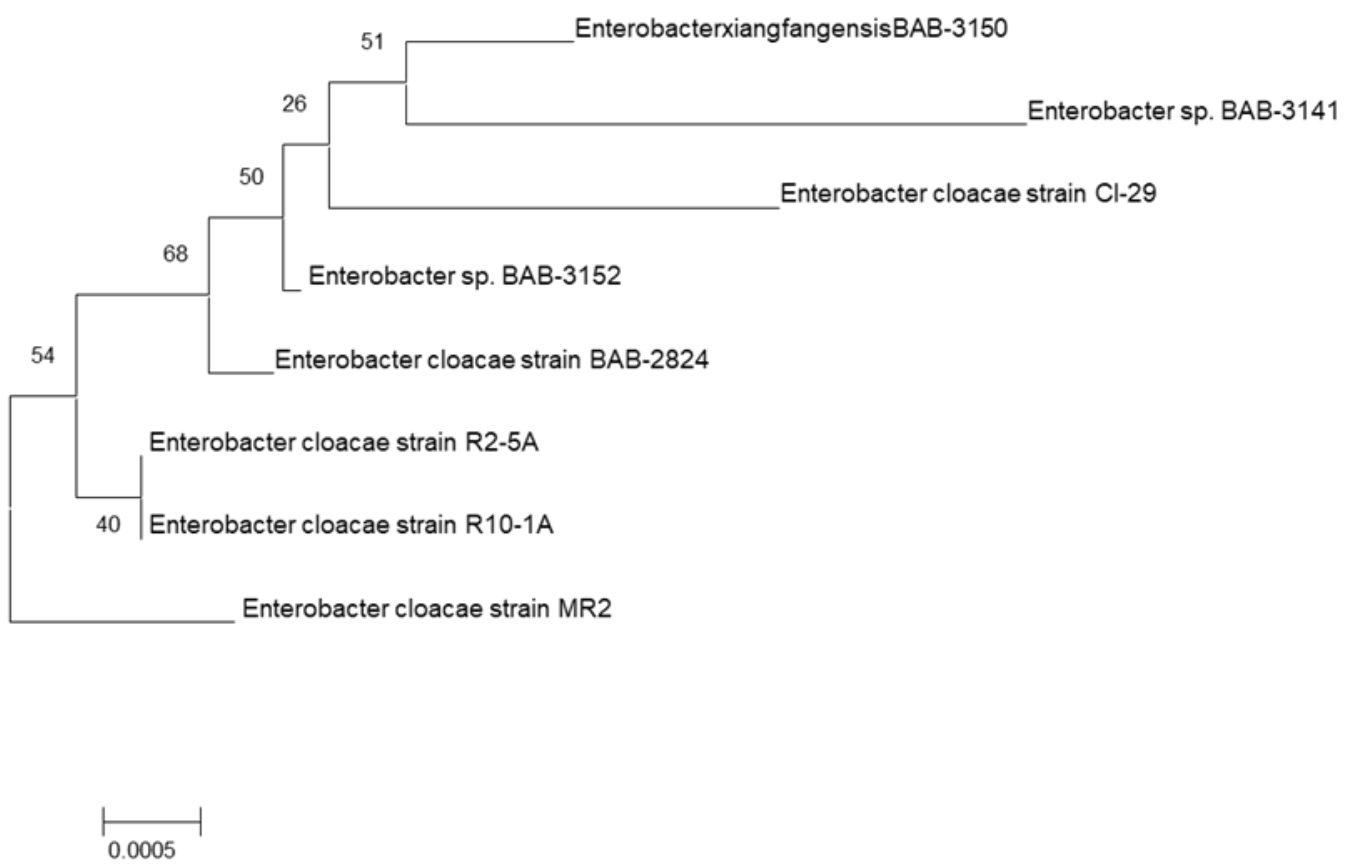

Figure. 4. Phylogenetic tree of Enterobacter xiangfangensis 
S37 16S ribosomal RNA gene, partial sequence

Ochrobactrum anthropi strain EGI60010 16S ribosomal RNA gene, partial sequence

- la-proteobacteria 9 leaves

Bacterium SNISO_E1 16S ribosomal RNA gene, partial sequence

bacteria $\mid 2$ leaves

Uncultured bacterium clone S4-4-CL3 16S ribosomal RNA gene, partial sequence

Ochrobactrum intermedium $16 \mathrm{~S}$ ribosomal RNA gene, partial sequence

Ochrobactrum sp. L115 16S ribosomal RNA gene, partial sequence

Bacterium enrichment culture clone S_2010_SML_1 16S ribosomal RNA gene, partial sequence

Ochrobactrum sp. MB6 16S ribosomal RNA gene, partial sequence

Uncultured Brucellaceae bacterium clone 9892 16S ribosomal RNA gene, partial sequence

Ochrobactrum intermedium strain SSR6 16S ribosomal RNA gene, partial sequence

Ochrobactrum intermedium gene for $16 \mathrm{~S}$ ribosomal RNA, partial sequence, strain: 182L

Ochrobactrum intermedium gene for $16 \mathrm{~S}$ ribosomal RNA, partial sequence, strain: $52 \mathrm{~A}$

Ochrobactrum sp. G5 16S ribosomal RNA gene, partial sequence

Ochrobactrum sp. DGG-1-3 16S ribosomal RNA gene, partial sequence

Uncultured bacterium clone TE $1 \mathrm{a} 05 \mathrm{~h} 3$ $92316 \mathrm{~S}$ ribosomal RNA gene, partial sequence

Uncultured bacterium clone FL2xb12_14626 16S ribosomal RNA gene, partial sequence

Uncultured bacterium clone C-60 16S ribosomal RNA gene, partial sequence

Fa-proteobacteria 4 leaves

Uncultured bacterium partial 16S rRNA gene, clone SICC470_N11D2_16S_B

a-proteobacteria $\mid 2$ leaves

Uncultured bacterium clone W031d5_1074 16S ribosomal RNA gene, partial sequence

Ochrobactrum intermedium strain RD_DACAR_08 16S ribosomal RNA gene, partial sequence

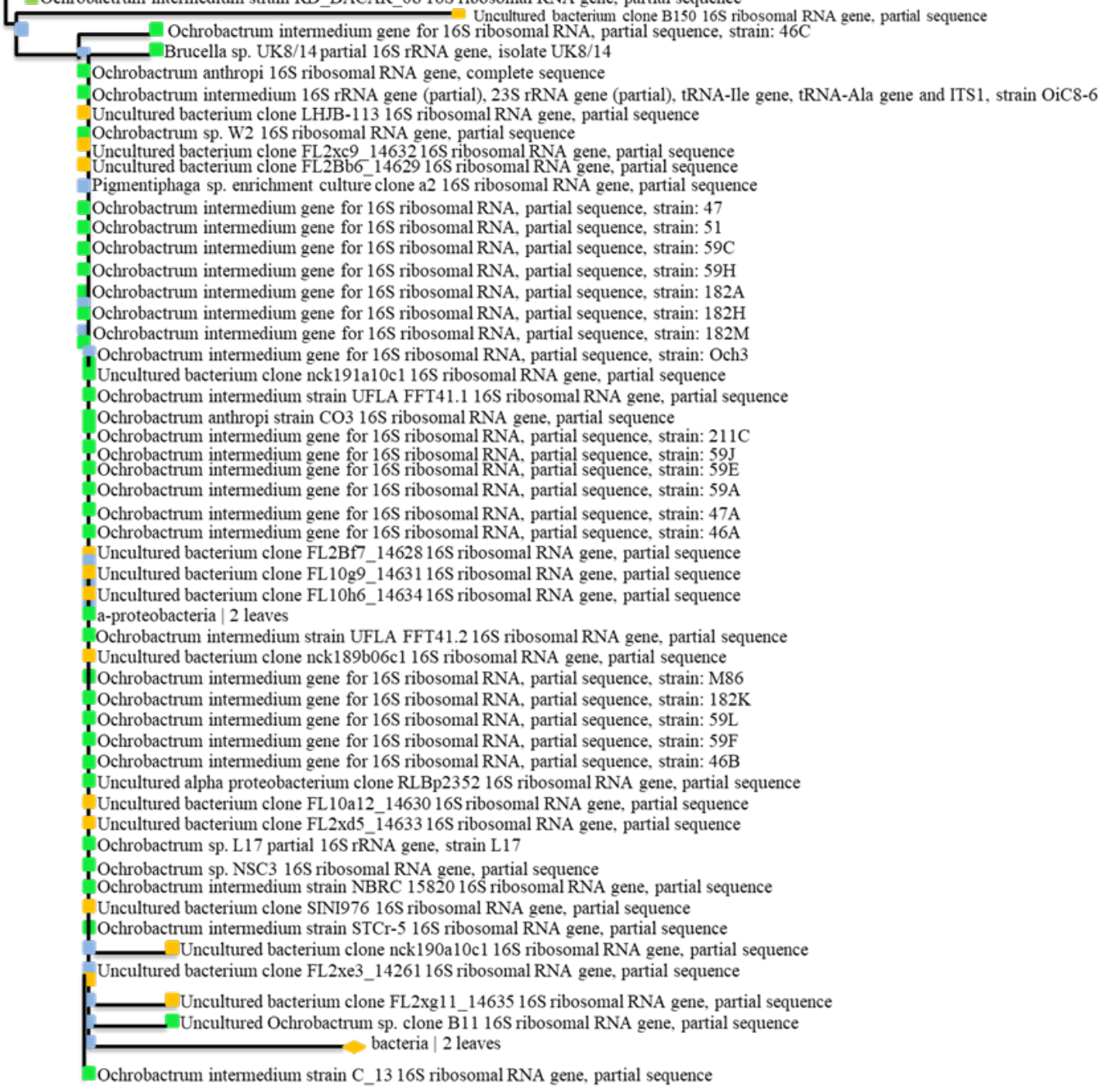

Figure 5. Phylogenetic tree of Ochrobactrum intermedium 


\section{Discussion}

Resistance of mosquitoes to insecticides and chemical agents have been increasing rapidly. Searching of new molecules from natural environments is expected in the next decade. In our study suggested that the identified three insect gut microbes have insecticidal property on mosquito larvae. However, the derivatives of microbes could reduce the mosquito population and may alter the use of synthetic insecticides.

Efforts have been made to fight against Anopheles gambiae to control malaria and arbovirus infections and various concentrations had to influence the mortality percentage [46]. In this study revealed that $B$. thuringiensis, $S$. aureus, $M$. sedentarius, E. faecalis and S. pneumonia had larvicidal activity. In consonance with another [47] suggested that mode of action of bacterial species towards larvae could be due to the toxin production during their sporulation.

Xenorhabdus and Photorhabdus bacterias have possessed insecticidal activities against Aedes aegypti [48, 49]. Here, the fed group of Xenorhabdus stockiae had the highest larvicidal activity against Aedes aegypti (99\% mortality) at $72 \mathrm{~h}$ after exposure and unfed group with $87 \%$ mortality at $96 \mathrm{~h}$ after exposure. Xenorhabdus indica had a high mortality rate against Aedes albopictus (82\%) at $96 \mathrm{~h}$ and unfed with $96 \%$ mortality rate at $96 \mathrm{~h}$. In accordance with our results exhibited that Klebsiella pneumoniae, Enterobacter xiangfangensis and Ochrobactrum intermedium had the highest larvicidal activity against Culex quinquefasciatus (100\%) at $24 \mathrm{~h}$.

Experimentally, B. thuringiensis were effective in reducing the density of immature dengue vectors due to the self-spreading properties of its monolayers [50]. Formerly, it has been found $B$. thuringiensis and B. sphaericus are effective against mosquito larvae and safe to non- target organisms [51]. The findings of this study suggested the demonstration of LLMLFourstar ${ }^{\circledR}$ in natural mosquito larval habitats will not alter the vertebrates and invertebrates inhabiting with mosquito larvae in the aquatic environment.

Protein inclusions in the range of $60 \mathrm{KDa}-150 \mathrm{KDa}$ existing in B. sphaericus can cause toxic effects to mosquito larvae [52]. In Caenorhabditis elegans cell death was triggered by the crystal toxins Cry6Aa- affecting the necrosis signalling pathway [53]. On the basis of this information, further studies are needed to identify the mechanism of action of three bacteria on Culex quinquefasciatus larvae to control mosquito community.

Klebsiella pneumoniae, Enterobacter xiangfangensis and Ochrobactrum intermedium have been isolated from the gut of E. alacris alacris, which have earlier been reported in the insect order of Dipterans and Lepidopterans [54]. Ochrobacterium intermedium also isolated from the gut of sand fly (Diptera: Psychodidae) and Phlebotomus duboscqi (Diptera: Psychodidae) [55, 56].
The three-insect gut microbial isolates, Klebsiella pneumoniae, Enterobacter xiangfangensis and Ochrobactrum intermedium caused persuasive mortality on the treated larvae. Likeways, species of Enterococcus and Enterobacter agglomerans isolated from Melanoplus sanguinipus showed insecticidal activity against agricultural pests. This result is in accordance with the metabolic action of $S$. citreofluorescens against mosquito larvae [57]. Exotoxins produced by the Pseudomonas species have been known to exhibit cytotoxicity against mosquito larvae [58].

\section{Conclusions}

To our knowledge, insecticidal activity of microbes screened from Eyprepocnemis alacris alacris gut was documented in the first time. Inference of this study suggested that enteric microbes in insects' gut could be used in order to produce bioactive compound against mosquito larvae.

\section{Conflict of Interests}

The authors declare that there is no conflict of interests regarding the publication of this paper.

\section{Acknowledgements}

The authors are thankful to Periyar University, Salem, Tamil Nadu, India for providing laboratory support.

\section{REFERENCES}

[1] WHO (World Health Organisation), Malaria- Factsheet No. 94. Geneva: WHO. 「Online] Available from:http://www.wh o.int/mediacentre/factsheets/fs094/en/, 2010.

[2] K. Balaraju, R. Maheswaran, P. Agastian, S. Ignacimuthu. Egg hatchability and larvicidal activity of Swertia chirata Buch. -Hams. ex Wall. against Aedes aegypti L. and Culex quinquefasciatus Say, Indian Journal of Science and Technology, Vol. 2, 46-49, 2009.

[3] R. Pavela. Larvicidal effects of various Euro-Asiatic plants against Culex quinquefasciatus Say larvae (Diptera: Culicidae), Parasitology Research, Vol. 102, 555-559, 2008.

[4] M. Govindarajan. Larvicidal and repellent properties of some essential oils against Culex tritaeniorhynchus Giles and Anopheles subpictus Grassi (Diptera: Culicidae), Asian Pacific Journal of Tropical Medicine, Vol. 4, 106-111, 2011.

[5] J.K. Udonsi. The status of human filariasis in relation to Clinical signs in endemic areas of the Niger Delta, Annual Tropical Medicine and Parasitology, Vol. 80, 425- 432, 1986. 
[6] L. Bernhard, P. Bernhard, P. Magnussen. Management of patients with lymphoedema caused by filariasis in north-eastern Tanzania: alternative Approaches, Physiotherapy, Vol. 89, 743-749, 2003.

[7] K.D. Ramaiah, P.K. Das, E. Michael, H. Guyatt. The economic burden of lymphatic filariasis in India, Parasitology Today, Vol. 16, 251-253, 2000.

[8] K. Myung, A. Massougbodji, S. Ekoue, P. Atchade, V. Kiki-Fagla, A.D. Klion. Lymphatic filariasis in a hyperendemic region: a ten- year, follow-up panel survey, American Journal of Tropical Medicine and Hygiene, Vol. 59, 222-226, 1998.

[9] M.A. Azmi, S.N.H. Naqvi, A. Kehkashan, A. Moinuddin, P. Shahida, P. Rehana, M. Aslam. Effect of pesticide residues on health and blood parameters of farm workers from rural Gadap, Karachi-Pakistan, Journal of Environmental Biology, Vol. 30, 747- 756, 2009.

[10] C. Makridis, C. Svarnas, N. Rigas, N. Gougoulias, L. Roka, S.V. Leontopoulos. Transfer of heavy metal contaminants from animal feed to animal products, Journal of Agricultural Science and Technology USA, Vol. 2, No. 1A, 149- 154, 2012.

[11] T. Chareonviriyaphap, M.J. Bangs, W. Suwonkerd, M. Kongmee, V. Corbel, R. Ngoen- Klan. Review of insecticide resistance and behavioral avoidance of vectors of human diseases in Thailand, Parasites \& Vectors, Vol. 6, 1- 28, 2013.

[12] N. Liu. Insecticide resistance in mosquitoes: impact, mechanisms, and research directions, Annual Review of Entomology, Vol. 7, 537- 559, 2015.

[13] U.R. Bernier, K.D. Furman, D.L. Kline, S.A. Allan, D.R. Barnard. Comparison of contact and spatial repellency of catnip oil and N, N-Diethyl-3-methylbenzamide (Deet) against mosquitoes, Journal of Medical Entomology, Vol. 42, 306- 311, 2005.

[14] R. Maheswaran, S. Ignacimuthu. Bioefficacy of essential oil from Polygonum hydropiper L. against mosquitoes, Anopheles stephensi and Culex quinquefasciatus, Ecotoxicology and Environment Safety, Vol. 97, 26-31, 2013.

[15] S. Leontopoulis, P. Skenderidis, G. Skoufogianni. Potential use of medicinal plants as biological crop protection agents, Biomedical Journal of Scientific and Technical Research Vol. 25, No. 4, 19320-19324, 2020.

[16] I.K. Vagelas, S.V. Leontopoulos, B. Pembroke, S.R. Gowen. Poisson and negative binomial modeling techniques for better understanding Pasteuria penetrans spore attachment on root-knot nematode juveniles, Journal of Agricultural Science and Technology USA, Vol. 2, No. 2A, 273-277, 2012.

[17] F.T. Gravanis, I.K. Vagelas, S.V. Leontopoulos, D. Natsiopoulos. Nematicidal effects of Azadirachta indica extract on Meloidogyne spp, Journal of Agricultural Science and Technology USA, Vol. 1, No. 1, 136-141, 2011.

[18] N.A. Moran. Symbiosis, Current Biology, Vol. 16, 866-871, 2006.

[19] R.F. Seipke, M. Kaltenpoth, I. Hutchings. Streptomyces as symbionts: A emerging and widespread theme, FEMS
Microbiology Review, Vol. 36, 862-876, 2012.

[20] R. Schunemann, N. Knaak, L.M. Fiuza. Mode of action and specificity of Bacillus thuringiensis toxins in the control of caterpillars and stink bugs in soybean culture, ISRN Microbiology, 1-12, 2014.

[21] K.G. Bellile, J.R. Vonesh. Bioinsecticide and leaf litter combination increases oviposition and reduces adult recruitment to create an effective ovitrap for Culex mosquitoes, Journal of Vector Ecology, Vol. 41, 123-127, 2016.

[22] P.S. Birthal, O.P Sharma. Integrated pest management in Indian agriculture, Chandu Press, New Delhi, India, 2004.

[23] L. Zhang, M. Lecoq, A. Latchininsky, D. Hunter. Locust and grasshopper management, Annual Review of Entomology, Vol. 64, doi: 10.1146/annurev-ento-011118-112500, 2019.

[24] C.J. Lomer, R.P. Bateman, D.L. Johnson, J. Langewald, M. Thomas, Biological control of locusts and grasshoppers, Annual Review of Entomology, Vol. 46, 667- 702, 2001.

[25] M.I. Kokkora, K.B. Petrotos, C. Papaioannou, P.E. Gkoutsidis, S.V. Leontopoulos, P. Vyrlas. Agronimic and economic implications of using treated olive mill wastewater in maize production, Desalination and Water Treatment, 1-7, 2016.

[26] P. Engel, N.A. Moran. The gut microbiota of insects diversity in structure and function, FEMS Microbiology Review, Vol. 37, 699- 735, 2013.

[27] A.E. Lang, G. Schmidt, J.J. Sheets, K. Aktories. Targeting of the actin cytoskeleton by insecticidal toxins from Photorhabdus luminescens, Naunyn Schmiedebergs Archieves in Pharmacology, Vol. 383, 227-235, 2011.

[28] P. Okullo, S.R. Moe. Large herbivores maintain termite-caused differences in herbaceous species diversity patterns, Ecology, Vol. 93, 2095- 2103, 2012.

[29] E.F. Acanakwo, D. Sheil, S.R. Moe. Termites and large herbivores influence seed removal rates in an African savanna, Ecology, Vol. 98, 3165-3174, 2017.

[30] H.G. Fowler, J. Justi. Field collection techniques for genera Neocurtilla and Scapteriscus mole crickets and their effect upon the evaluation of their natural pathogens in Brazilian, Journal of Applied Entomology, Vol. 104, 204- 207, 1987.

[31] D.S. Porto, G.A.R. Melo, E.A.B. Almeida. Clearing and dissecting insects for internal skeletal morphological research with particular reference to bees, Review of Brasillian Entomology, Vol. 60, 109- 113, 2016.

[32] A.M. Scrivener, M. Slaytor, H.A. Rose Symbiont-independent digestion of cellulose and starch in Panesthia cribrata Saussure, an Australian wood-eating cockroach, Journal of Insect Physiology, Vol. 35, 935- 941, 1989.

[33] J. Sambrook, T. Maniatis, E.F. Fritsch. Molecular cloning: a laboratory manual, $2^{\text {nd }}$ Ed., Cold Spring Harbor Laboratory, New York, 1989.

[34] H. Watanabe, M. Nakamura, G. Tokuda, I. Yamaoka, A.M. Scrivener, H. Noda. Site of secretion and properties of endogenous Endo-/3-1, 4-glucanase components from Reticulitermes speratus (Kolbe), a Japanese subterranean 
termite, Insect Biochemistry and Molecular Biology, Vol. 27, 305- 313, 1997.

[35] M. Wenzel, I. Schonig, M. Berchtold, P. Kampfer, H. Konig. Aerobic and facultatively anaerobic cellulolytic bacteria from the gut of the termite Zootermopsis angusticollis, Journal of Applied Microbiology, Vol. 92, 32-40, 2002.

[36] S.V. Patil, C.D. Patil, R.B. Salunkhe, B.K. Salunke. Larvicidal activities of six plants extracts against two mosquito species, Aedes aegypti and Anopheles stephensi, Tropical Biomedicine, Vol. 27, 360-365, 2010.

[37] R. Maheswaran, S. Sukumaran, G. Nattudurai, S. Ignacimuthu. Bioefficacy of essential oil from Toddalia asiatica (L.) Lam. against dengue vector mosquitoes Aedes aegypti L. and Aedes albopictus Skuse, Indian Journal of Natural Products and Resources, Vol. 7, 245- 251, 2016.

[38] WHO (World Health Organization). The use of essential drugs. Seventh report of the WHO Expert Committee, Geneva, (WHO Technical Report Series, No. 867), 1997.

[39] S.I. Mohammed, K.S. Vishwakarma, V.L. Maheshwari. Evaluation of larvicidal activity of essential oil from leaves of Coccinia grandis against three mosquito species, Journal of Arthropod-Borne Disease, Vol. 11, 226-235, 2017.

[40] D.J. Finney. Probit Analysis, Cambridge University Press, New York, 1971.

[41] P. Holt, U. Holmskov, S. Thiel, B. Teisner, P. Højrup, J. C. Jensenius. Purification and characterization of mannan binding protein from mouse serum, Scandinavian Journal of Immunology, Vol. 39, 202-208, 1994.

[42] X.Z. Dong, M.Y. Cai. Determinative manual for routine bacteriology, Beijing: Scientific Press, 2001.

[43] U. Edwards, T. Rogall, H. Blocker, M. Emde, E.C. Bottger. Isolation and direct complete nucleotide determination of entire genes. Characterization of a gene coding for $16 \mathrm{~S}$ ribosomal RNA, Nucleic Acids Research, Vol. 17, 7843-7853, 1989.

[44] G. Talavera, J. Castresana. Improvement of phylogenies after removing divergent and ambiguously aligned blocks from protein sequence alignments, Systematic Biology, Vol. 56, 564-577, 2007.

[45] A. Dereeper, V. Guignon, G. Blanc, S. Audic, S. Buffet, F. Chevenet, J.F. Dufayard, S. Guindon, V. Lefort, M. Lescot, J.M. Claverie, O. Gascuel. Phylogeny. fr: robust phylogenetic analysis for the non-specialist, Nucleic Acids Research, Vol. 36, W465- W469, 2008.

[46] T.O. Ndibe, W.C. Eugene, J.J. Usman. Screening of biosurfactant-producing bacteria isolated from river Rido, Kaduna, Nigeria, Journal of Applied Sciences and Environmental Management, Vol. 22, 1855-1861, 2018.

[47] K. Gammon, G.W. Jones, S.J. Hope, C.M.F. de Oliveira, L. Regis, M.H.N.L.S. Filha, B.N Dancer, C. Berry. Conjugal transfer of a toxin-coding megaplasmid from Bacillus thuringiensis subsp. israelensis to mosquitocidal strains of
Bacillus sphaericus, Applied and Environmental Microbiology, Vol. 72, 1766-1770, 2006.

[48] A. Vitta, P. Thimpoo, W. Meesil, T. Yimthin, C. Fukruksa, R. Polseela, B. Mangkit, S. Tandhavana, A. Thanwisai. Larvicidal activity of Xenorhabdus and Photorhabdus bacteria against Aedes aegypti and Aedes albopictus, Asian pacific Journal of Tropical Medicine, Vol. 8, 31-36, 2018.

[49] G. Skoufogianni, V. Anatolioti, S. Leontopoulos. Efficacy of the entomopathogenic bacteria Xenorhabdus nematophilus and Xenorhabdus bovienii on different developmental stages of Phaedon cochleariae, $4^{\text {th }}$ I.C., Crete Island 30/05-02/06/19, FaBE Proceedings, 365-381, 2019.

[50] G.M. Roberts. Spreading of Bacillus thuringiensis var. israelensis over the water surface by a monolayer carrier, World Journal of Microbiology and Biotechnology, Vol. 7, 335-342, 1991.

[51] Y.A. Derua, S.C. Kahindi, F.W. Mosha, E.J. Kweka, H.E. Atieli, X. Wang, G. Zhou, M. Lee, A.K. Githeko, G. Yan. Microbial larvicides for mosquito control: Impact of long lasting formulations of Bacillus thuringiensis var. israelensis and Bacillus sphaericus on non - target organisms in western Kenya highlands, Ecology and Evolution, Vol. 8, 7563- 7573, 2018.

[52] P. Baumann, M.A. Clark, L. Baumann, A.H. Broadwell. Bacillus sphaericus as a mosquito pathogen: properties of the organism and its toxins, Microbiology Reviews, Vol. 55, 425-436, 1991.

[53] F. Zhang, M. Berg, K. Dierking, M. Felix, M. Shapira, B.S. Samuel, H. Schulenburg. Caenorhabditis elegans as a model for microbiome research, Frontiers in Microbiology, Vol. 8, 485, 2017.

[54] S. Madhusudan, S.K. Jalali, T. Venkatesan, Y. Lalitha, R.P. Srinivas. 16S rRNA gene based identification of gut bacteria from laboratory and wild larvae of Helicoverpa armigera (lepidoptera: noctuidae) from tomato farm, The Biosan, Vol. 6, 175-183, 2011.

[55] M.R.V. Sant'Anna, H. Diaz-Albiter, K. Aguiar-Martins, W.S Al Salem, R.R. Cavalcante, V.M. Dillon, P.A. Bates, F.A. Genta, R.J. Dillon. Colonisation resistance in the sand fly gut: Leishmania protects Lutzomyia longipalpis from bacterial infection, Parasite Vectors, Vol. 7, 1-10, 2014.

[56] P. Volf, A. Kiewegová, A. Nemec. Bacterial colonisation in the gut of Phlebotomus duboscqi (Diptera: Psychodidae): transtadial passage and the role of female diet, Folia Parasitology, Vol. 49, 73-77, 2002.

[57] G. Singh, S. Prakash. Lethal effect of Streptomyces citreofluorescens against larvae of malaria, filaria and dengue vectors, Asian Pacific Journal of Tropical Biomedicine, Vol. 5, 594-597, 2012.

[58] M.G. Murty, G. Srinivas, V. Sekar. Production of a mosquitocidal exotoxin by a Pseudomonas fluorescens strain, Journal of Invertebrate Pathology, Vol. 64, 68-70, 1994. 